\section{A Aemontration}

\author{
ON
}

\section{(ONSTRICTIONS AND OCCLUSIONS OF THE ALIMENTARY TRACT OF CONGENITAL} OR OBSCURE ORIGIN

Given at the Royat College of Surgeons, England, BY

Professor arThUR KeITH, M.D., F.R.C.S.Eng., CONBERVATOR OF THE MUSEUM.

Tre statistical list which I subjoin gives not only the subject-matter of this demonstration, but shows to what extent congenital occlusions and constrictions of the alimentary tract are represented by preparations in the various metropolitan medical museums. Under colnmn A are grouped the specimens in the Museum of the Royal College of Surgeons, England, and under column B those in the museums of the medical schools attached to the various hospitals in London, to the authorities of which I am greatly indebted for the many privileges they have extended to me.

\section{I.ist of Specimens showing Constrictions and Occlusions of the Alimentary Tract of Congenital or Obscure Origin in the Medical Museums of London.}

\begin{tabular}{|c|c|c|c|}
\hline & A. & B. & Total. \\
\hline $\begin{array}{l}\text { I. Non-cicatricial stenosis of the upper oeso- } \\
\text { pliageal orifice }\end{array}$ & 4 & 5 & 9 \\
\hline $\begin{array}{l}\text { II. Stenosis of the lower oesophageal oriflce, with } \\
\text { dilatation of the oesophagus }\end{array}$ & 2 & 4 & 6 \\
\hline III. Congenital stenosis of the mid-oesophagus ... & 0 & 2 & 2 \\
\hline $\begin{array}{l}\text { IV. Malformation of the tracheo-oesophageal } \\
\text { septum }\end{array}$ & 5 & q & 14 \\
\hline v. Hour-glass constriction of the stomach & 4 & 10 & 14 \\
\hline VI. Hypertrophic stenosis of the pylorus $\ldots$ & 2 & 12 & 14 \\
\hline VII. Congenital occlusion of the duodenum... & 1 & 6 & 7 \\
\hline $\begin{array}{l}\text { VIII. Congenital occlusions and constrictions of the } \\
\text { jejunum and ileum (not including those } \\
\text { associated with a Meckel's diverticulum) }\end{array}$ & 6 & 9 & 15 \\
\hline IX. Congenital occlusion at the ileo-caecal junction & 1 & 0 & 1 \\
\hline x. Congenital occlusion of the colon... $\quad \ldots \quad \ldots$ & 0 & 4 & 4 \\
\hline & 29 & 57 & 86 \\
\hline
\end{tabular}

Non-cicatricial Stricture at the Commencement of the Oesophagus.

In the Musenm of the Royal College of Sargeons, England, there are four specimens, two of which belong to the original Hunterian collection, showing a marked narrowing at the commencement of the oesophagus. Such strictures are usually regarded as the result of a serere and localized inflammation, but in the specimens $I$ here illustrate there is no clear evidence of cicatrization (Fig. 1). The condition and such clinical histories as are available point to a disturbance in the normal mechanism of the oesophagus. In the Museum of St. George's Hospital School there are three specimens of a similar nature, and in that of Charing Cross Hospital there are two more, making nine in all. The condition was described and investigated by Sir Everard Home.1 The specimen (No. 2295) was presented to the College Museum by him, and is shown in Fig. 1. From various observations in health and disease, he concluded that the upper part of the oesophagus acted as a sphincter-he compares it to the constrictor of the urethra-and that under certain pathological conditions the contraction of the upper sphincter of the oesophagus may become permanent It is not my present purpose to whitewash the reputation of Sir Everard Home, yet I foel that it is a misfortune to medical science that the obloquy which has justly overtaken his moral reputation, on account of the destruction of Hunter's manuscripts, should have been extended to his own writings. 3
The lectures which he delivered at this college, just a century ago, contain many observations and diseoverien probably inspired by Hunter, yet not made by Huntre, which deserve to be again brought into common know. ledge. The existence of an upper oesophageal sphincter is one; the presence of a functional mid-gastria sphincter is another. Like the sphincter at the pylorus, that at the upper end of the cesophagus is continually in action, except during the initial act of swallowing. It is a wellknown fact that, on passing a stomach tube, a temporary resistance is encountered when the point of the instrument enters the oesophagus, but beyond this point, as Drs. Souttar and Thompson observed when passing their gastroscope, the rest of the oesophagus, until the cardiac orifice is reached. is flaccid and open. The resistance offered at the commencement of the oesophagus is due to the tonicity of the sphincter which guards the upper orifice. In the specimens which illustrate stenosis of the upper cesophageal orifice the condition seen in eight of the specimons is not comparable to a hypertrophic but to a fibrous stenosis of the pylorus. The circular muscle is not hypertrophied but

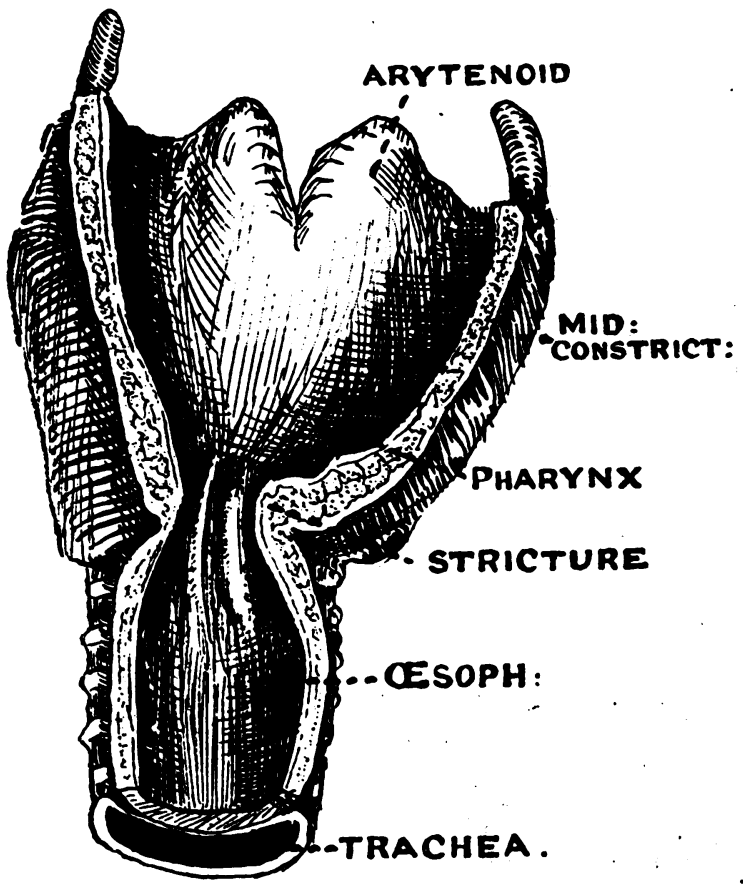

Fig. 1.-Drawing of the preparation (No. 2295) presented bs Sir Everard Home, Bart. to the Museum of the Royel College of Surgeons. Fngland, to illustrate non-cicatricial constriction of its upper orifice).

atrophied, contracted and replaced by loose connectire tissue. In one of the specimens there is a hypertrophy of the musculature.

Cicatricial Contraction of the Upper Oesophageal Orifice.

I am also able to show a specimen of cicatricial stenosis at the upper aperture of the oesophagus, the result of the inflammation set up by the swallowing of sulphuric acid. I noted four similar specimens in the musenms of the London medical schools; in all the corrosive actipy was limited to or affected chiefly the upper inch of the oesophagus, a result that is explained by the sphincter-like action of the muscle of this part. A description of this sphincter will be given in my next demonstration, in connexion with diverticula of the pharynx.

\section{Stenosis of the Lower Oesophageal Orifice and Dilatation of the Oesophagus.}

In the two specimens of "idiopathic" dilatation of the oesophagus in the college museum and in four others to be seen in the museums of metropolitan medical sohools the commencement and termination of the oesophagus have not shared in the general dilatation. In this pathological dilatation the terminal or sphincteric parts of the oesophagus have not shared. Indeed Lerche ${ }^{2}$ and several others ${ }^{3}$ have ascribed the dilatation of the oesophagus to a vitiated action of the lower or cardiac sphincter. Dr. A. F. Hertz ${ }^{4}$ has given a minute account of this sphincter so far 
as it can bo observed in transilluminations of the body during the act of swallowing bismuth-laden food.

W. H. F. Fhlers's has described the condition of hypertrophy and dilatation of the oesophagus in connexion with hypertrophic stenosis of the pylorus; all the evidence at present at our disposal indicates that dilatation and hypertrophy of the cesophagus is due to a pathological action and hypertrophy of the lower cesophageal ephincter. In one specimen I observed that the submucous coat was enormously increased, and that the circular muscular coat, although greatly hypertrophied, showed a peculiair degeneration in its fibres. In preparation No. 2321 this sphincter is greatly hypertrophied.

Congenital Stenosis of the Mid.part of the Oesophagus.

In newly-born children, that part of the cesophagns which lies in the posterior mediastinum and extends from the bifurcation of the trachea to within 1 or $2 \mathrm{~cm}$. of the diaphragm may be reduced to a fibrous imper. forate cord. The illustration given here (Fig. 2) is taken from a specimen in the museum of the medical school of St. Thomas's Hospital; there is a similar specimen in the musenm of the Middlesex Hospital School. The condition is allied to the abnormalities to be described in the next group,

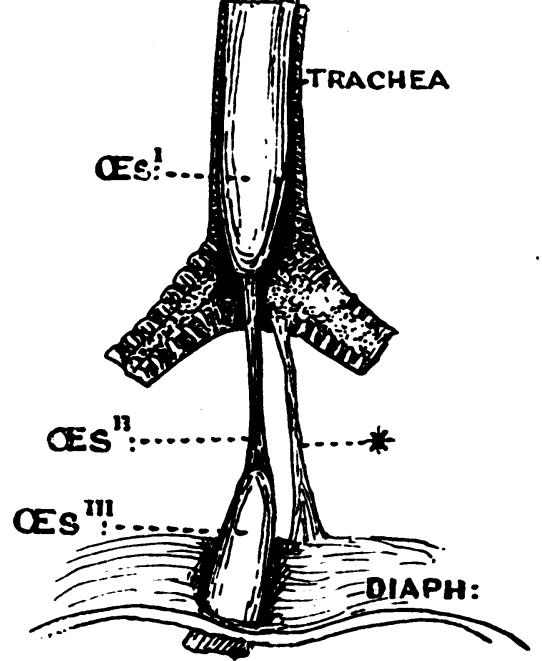

Fig. 2.-Congenital stenosis of the cesophagus in a newly-born child. Oes ${ }^{1}$ the retrotracheal part of the oesophagus Oes the imperforate part: Oes111, the supradiaphragmatic part; * muscular strand from the right isronchus to the
diaphragm.

lower segment from the trachea, and there was usually a greater or less degree of union between the musculature of the two segments of the oesophagus and that of the trachea.

The arrangement of parts is incompatible with life; to. reach the stomach, food must pass by the larynx, trachea, and the lower part of the oesophagus which opens from the trachea. The great majority of children with this malformation die in the latter half of the first. week of life, but one case at least lived until the twelfth day. Every. attempt to suckle ends in an attack. which threatens suffocation. Operative measures to unite the two segments. of the oesophagus are theoretically possible, but the technical difficulties are very great, and, so far as I know. operation has never been attempted. The diagnosis rests in finding the obstruction at a point 8 to $10 \mathrm{~cm}$. from the lips.

The condition here described is usually regarded as an atresia of the oesophagus, but it is more than thatit is a maldevelopment of the septum between the oesophagus and trachea. A study of the evolution and development of the trachea and oesophagus provides a key to this malformation. The trachea is a comparatively recent structure in its evolution; it appears with the demarcation of a but a satisfactory explanation of this lesion has not yet been given. It is certainly associated with an elongation of the oesophagus which occurs during the development and growth of the langs, and with the fact that in one stage of development (in human embry os of the second month) the oesophagus undergoes a temporary occlusion. ${ }^{\mathrm{ba}}$

Irregular Beparation of

the Trachea from the Oesophagus.

Examples of this condition, usually reported under the title of atresia of the oesophagus, are not of uncommon occurrence. There are five examples in the college collection and nine in the museums of the metropolitan medical schools.

In all 14 specimens the arrangement of parts is remarkably similar; the condition shown in Fig. 3 may be regarded as typical. The upper part of the oesophagus ends blindly at a point some distance above the bifurcation of the trachea; the lower part of the cesophagus springs from the posterior wall of the trachea as a narrow tube, and gradually in. creases to its norma calibre as it approaches the diaphragm and stomach. The opening from the traches to the lower part of the cesophagus in the specimens exsmined
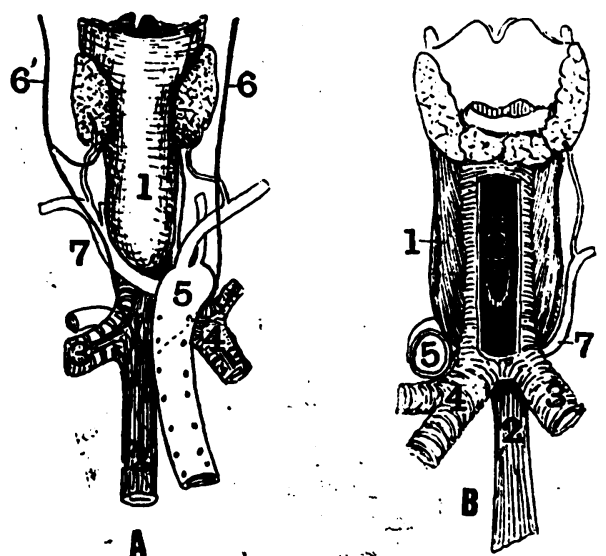
neck. In the amphibis the tracher and bronchi are absent; the lungs spring directly from the larynx. The oesophagus is little more than a sphincter between pharynx and stomach. When a neck appears, the posterior part of the overlying part of the pharynx are elongated to form the trachea, bronchi. and the corresponding part of the oesophagus. Their common origin is seen in their common nerve supply from the recurrentlaryngeal nerves. To interpret the appearances seen during the development of the trachea in the mammalian embryo, one must apply the knowledge gained from a study of the comparative anatomy of the parts. The larynx and the trachea appear in the human em. bryo towards the end of the third week as a gutter in the floor of the primitive foregut; the margins of this groove fuse to form the trachea-oesopha. geal septum, out of which the posterior wall of the trachea and anterior wall of the oesophagus are differentiated. The processes of fusion begin behind and spread uninter. ruptedly forwards. In normal development the union of the tracheal margins - takes place simultaneously with the elon. gation of the foregut. Clearly, in the malformations with which we are

Fig. 3.-Figures illustrating irregular separation of the trache from the oesophagus. $A, B$, and $C$, Dorsal, ventral, and lateral views of a case reported by Keith and Spicer in the Journ. Anat. and Phys., 1907, vol. xli. p. 52 . 1, Upper part of oesophagus ending in a cul-de-sac; 2 . lower part arising from posterior wall of trachea ; 3,4 , left and right bronchi ; 5 , arch of aorta; 6 , vagus ; 7 , right subclavian artery arising as last branch of the aortic arch; 8 , opening in traches for lower part of oesophegus wo The regular and irregular formation of the septum betreen trachea and oesophagus. was situsted somewhere in the posterior wall of the lower half of the trachea; in the majority the opening was at the junction of the upper three-fourths with the lower lourth. In 12 of the 14 specimens the fundas of the upper aegment of the oesophagus overlapped the origin of the dealing, the lateral margins of the tracheal groove, instead of meeting behind on the floor of the foregut, meet on its dorsal wall; hence, when they fuse, the septum between the trachea and oesophagus is laid down in the position shown in $\mathrm{D} \mathbf{E}$, Fig. 3, in place of the normal position shown in $D, F i g .3$. 
The break in the oesophagus occurs at what I believe is the junction of two morphological parts. The upper part is derived from the pharynx; its muscular fibres are chiefly, almost entirely, striated fibres, a fact which Luschka had discovered many years before me, as may be seen in Ballantyne's excellent book. ${ }^{6}$ The lower part is derived from the primitive oesophagus, and is coated with ron-striated fibres. In this malformation the primitive oesophagus ends in the trachea, a derivative of the primitive pharynx.

Cases have been described in which a congenital fistula existed between the trachea and oesophagus; we have no specimen of this condition in London collections, nor is there one in which the lower part of the oesophagus opens from the left bronchus. These forms can be accounted for by an irregular or interrupted fusion of the tracheal margins of the embryo; cases have also been seen in which the upper cul-de.sac of the oesophagus communicated with the trachea by a fistala.

Mr. Bland.Sutton has pointed out how often congenital constrictions of the alimentary canal occur at the paints where developmental diverticula occur. Mr. Shattock? regards the atresia of the oesophagus as being determined by the outgrowth of the lung buds, the process of evagina. tion incolving the whole thick. ness of the foregut instead of being confined to its ven. tral wall. A study of the associated malformations throws some light on the nature of this lesion. Happich found that in 28 cases out of 59 there were other abnormalities, such as an imperforate anus, pulmonary stenosis, club-foot, spina bifida. In three consecutive cases, $\mathrm{Dr}$. Spicer and I found that there was a persistence of the left aortic arch; but the persistence of this arch, although common, is not constant. Morell Mackenzie $^{8}$ collected 63 published cases of malformation of the oesophagus in $1884 ; 43$ of them were of the nature described here. Drs. Crozer Griffith and R. S. Lavenson ${ }^{9}$ have given a summary of re cently published cases.

\section{Hour-Glass Constriction of Stomach.}

Although an hour-glass constriction of the stomach cannot be regarded as of uncommon occurrence, yet there are remark. ably few specimens in the metro. politan medical museums. I saw fourteen in all, four of them being in the museum of this college. All the specimens agree in having the cardiac part sharply marked off from the pyloric by a constriction, but the form of the constriction is not quite alike in any two of them; in some the constriction is annular, notching both the lesser and greater curvatures of the stomach, or only the lesser curvature may be involved. In more than half of the cases the connexion between the two compartments of the stomach was tubular in form, the inter mediate narrow part being 1 in. or more in length.

As to the nature of the mid-gastric constriction, one must remember that the condition has never been -observed at birth ; there is no evidence of maldevelopment producing the constriction. Sir Everard Home was the first to form a definite conception of its nature. In his Hunterian lectures, delivered nearly 100 years ago in this theatre, he described how his observations on the living stomach had convinced him that it was made up of two fanctional parts-a cardiac and pyloric-and that these two parts were separated in life by a mid.gastric sphincter. In hour-glass stomach the contraction of the mid-gastric sphincter became permanent, in the same manner and for the same obscure reasons as happens at the upper oesophageal and pyloric orifices. The results gained by Canon, by Hertz, and by Gray, ${ }^{10}$ in studying the mechanism of gastric digestion, have confirmed and extended Home's observations; so, too, have the anatomical studies of the late Professor Cunningham."11 The mid-gastric sphincter differs from the musculature at the oesophageal, pyloric and ileo caecal orifices in being active only during digestion, whereas the others are always in action. Home also observed that the action of the mid-gastric sphincter might be lost in certain cases of disease-a conclusion which Dr. W. H. M. Gray reached from his study of clinical cases by the aid of $x$ rays. The mid.gastric sphincter of the stomach is certainly not an anatomical entity, but must be regarded as the commencement of the pyloric part of the stomach. Mayo Robson ${ }^{12}$ and Mopnihan ${ }^{13}$ regard hour-glass constriction as always the result of a pathological process; Tobin found that in only 1 of 6 cases was there evidence of cicatrization. I agree that in the majority of cases this constriction is a result of ulceration, but the narrowing is determined by cicatrization occurring in that part of the stomach which is kept in a state of tonic contraction by the mid-gastric sphincter. Ulceration may occur at any part of the stomach, but this constriction occurs between the cardiac and pyloric divisions.

Hypertrophic Stenosis of the Pylorus.

There is not a single specimen in the metropolitan medical museums of a stenosis of the pylorus in a fetus or newly-born child. Of the fourteen museum specimens illustrating this condition, only two of which are in the college collection, not one is from a child less than one month old. Many of these specimens are also unsatisfactory for the reason that their appearance depends on the manner of preservation, the varying length of time which elapsed after death before they were fixed by preservatives, and the degree of contraction present in the sphincter at the time of fixation. The pyloric region of the stomach of healthy children shows a wide variation in development. In only eight of the fourteen specimens was a longitudinal section of the pylorus shown. In these the muscu. lature at the pylorus measured 2.5 to $3 \mathrm{~mm}$. in thickness, whereas the thickness in normal children of a corresponding age
but all these measurements vary amounts to 1.5 to $2 \mathrm{~mm}$., but all these measurements vary dition appears to result from a functional derangement. Beyond the muscular hypertrophy there is no pathological manifestation.

Congenital Occlusion of the Duodenum.

The only specimen representing congenital occlusion of the duodenum in the college collection is one recently presented by Mr. Ernest Shaw, but it is typical of the other seven specimens which I have examined, six in metropolitan medical museums, and one in the University Museum of Leeds. Mr. Shaw's specimen is shown in Fig. 5. Immediately above the entrance of the common bile duct the duodenum is occluded by a septum, which is covered on each side by mucous membrane, and contains muscular strata continuous with the muscular coats of the bowel. In two cases an accessory pancreatic duct can be seen to open in the duodenum above the septum. In one case the occlusion is represented by, not a septum, but an annular constriction, showing that in this lesion there is an arrest of development of a segment of the duodenum. A specimen in the museum of St. Bartholomew's Hospital (No. 3635E ${ }^{1}$ ) was obtained 
from a very remarkable case. The child lived for nine months, although the occlusion of the duodenum was complete. It had recurrent fits of vomiting, and passed very little per anum. The medical men who reported the case thought there must have been some other passage for the food than that by the duodenum. Sir Everard Home found that absorption from the stomach took place in the dog after the duodenum had been tied; in the case of this child absorption was apparently sufficient to keep it in life for nine months. Besides the eight specimens mentioned above there were three others showing variations of this condition. One in the museum of St. Mary's

Hospital Medical School is remarkable. Thedilated duodenum of an adult is crossed by a diaphragm above the opening of the common bile duct. In the diaphragm, which is ballooned downwards into the second stage of the duodenum, there is an oval orifice measuring about 5 by $3 \mathrm{~mm}$. In another specimen (No. 3635 B, St. Bartholomew's Hospital) the occlusion occurs at the usual point, but the duodenum beyond the occlusion and the first part of the jejunum are obliterated. A specimen in the college museum obtained from Mr. Liston's collection shows a constriction of the duodenum just beyond the pylorus.

Why occlusion should occur in the Vaterian segment of the duodenum is not very apparent. It is probably associated, as Mr. Bland-Sutton has inferred, with the outgrowth of the embryonic buds of the liver and pancreas. It occurs at the junction of two morphological parts of the alimentary tract- the fore and mid gut. Congenital occlusions of the bowel have been recently investigated by a Swedish anatomist, Hjalmar Forssner, ${ }^{14}$ who finds, as Professor Tandler had found some years before; that the Vaterian segment of the duodenum is occluded by the proliferation of its epithelial lining during the greater part of the second month of development-a form of occlusion which also occurs in the oesophagus and many parts of the small and large bowel. The epithelial plug, failing to break down as development proceeds, leads to an occlu. sion of the bowel at that point. Cases of this nature have been recently reported by Mr. H. S. Clogg. ${ }^{15}$

\section{Congenital Constrictions and Occlusions of the Jejunum.}

Malformations of the jejunum are variable in shape and position. Of the eight museum specimens representing this lesion, three of which are in the college collection, not

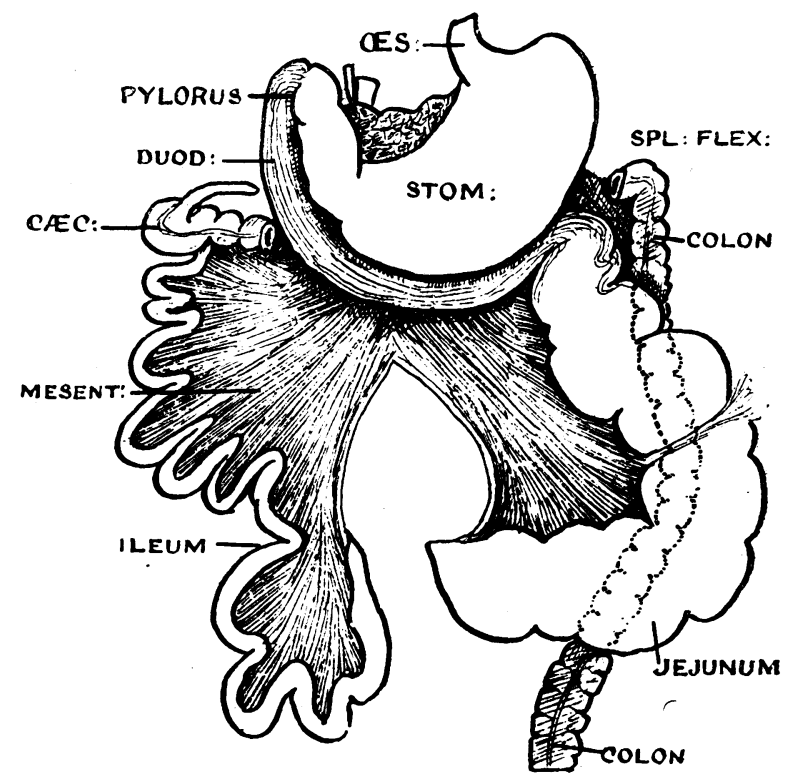

Fig. 6.-Congenital atresia of a segment of the jejunum with a $v$-shaped oap in segment of the

diameter of the upper segment was $25 \mathrm{~mm}$., that of the lower $9 \mathrm{~mm}$. At the point of interruption there is a. V-shaped gap in the mesentery (Fig. 6), with a smooth but thin edge. In a similar case, Bergallonne ${ }^{16}$ found a threadlike margin to the mesenteric gap, the thread representing the two outer coats of the bowel. The exact lesion which causes a localized atresia of the intestine can only be guessed at, for until the end of the third week of embryonic life the jejunum, ileum, and proximal part of the colon are represented by the short segment of gut which overlies the yolk sac. The manner in which this short segment becomes rapidly elongated, thrown into coils, and separated from the yolk sac is at presentimperfectly understood. Forssner ${ }^{14}$ attributes the occlusions to a persistence of the epithelial plugs which close the bowel in the second month of development. Altogether I saw 8 cases of congenital constriction or occlusion of the jeju. num. Three cases were of the type just described, where a segment was absent altogether or represented merely by a thread on the edge of the mesen. tery; in 2 there were multiple defects ; in 2 the lumen of the bowel was open, but the passage of contents was prevented by a septum; in 1 there was merely a localized narrowing or stricture. J. E. Emmanuel ${ }^{17}$ reported the case of a seventh-month child with multiple constrictions of the jejunum, which lived for nine days. In 31 cases of congenital constriction of the small bowel Hirschsprung found that the lesion was. situated in the duodenum in 16, at the ileo-caecal junction in 6 , and between these points in 9 .

Congenital Occlusion of the Ileum.

A narrowing of the ileum is often associated with the presence of a Meckel's diverticulum; it is usually situated proximal to the diverticulum, but may be distal or opposite to it. I have seen several cases in which the bowel was re. duced to half or less of its normal lumen at a distance of $2 \mathrm{ft}$. or $3 \mathrm{ft}$. above the ileo-caecal junction; these constrictions apparently occur at the same site as Meckel's diverticulum, and are associated with the atrophy of the yolk sac. The process of atrophy: which normally overtakes the stalk of the yolk sac, appears, in these cases, to extend to the neighbouring bowel. Of the seven museum specimens illustrating congenital occlusion of the ileum, one shows a complete break in the continuity of the bowel at a point $2 \mathrm{ft}$. above the ileocaecal junction; in two the terminal part of the ileum. any two are exactly alike.

In Fig. 6 I represent the 列 Hospital some years ago-that of a child who died on the third day after birth with all the symptoms of acute intestinal obstruction. The continuity of the jejunum is interrupted above the ileo.jejunal junction, the total length of the small bowel being $135 \mathrm{~cm}$. The upper seg. ment is distended and elongated by the intestinal contents, while the lower segment is contracted and contains a considerable amount of meconium-like material. The is absent, the defect apparently commencing at the usual site of a Meckel's diverticulum; in one the terminal part of the ileum is reduced in size, the reduction commencing at Meckel's point; in one a diaphragm crosses the lumen of the bowel at this point; in one the defects are multiple; in the seventh preparation the occlusion is apparently due to adhesive bands resulting from fetal peritonitis. A remarkable pre. paration (No. 45 Museum of St. Bartholomew's Hospital) may be placed in this group, although it repre. 
sents an arrest of growth of the whole of the small intestine. The preparation was obtained by Mr. Abernethy from a boy aged 12 years, in whom the small bowel was only $2 \mathrm{ft}$. in length; the colon measured $4 \mathrm{ft}$. Mr. H. S. Clogg ${ }^{15}$ has recorded two very instructive cases of occlusion of the ileum; in one the ileum at Meckel's point was reduced to a thread; in the other the small intestine, which lay within an umbilical hernia, showed a complete absence of the segment of the bowel in the neighbourhood of Meckel's point. Dr. D. Waterston ${ }^{18}$ has also reported a case in which the ileum near Meckel's point was absent, the corresponding part of the mesentery showing a $\mathfrak{V}$-shaped deficiency.

\section{Occlusion at the Ileo-caecal Junction.}

Although cases of congenital occlusion at the ileo-caecal junction have been recorded, there are no representatives of the lesion in the metropolitan maseurns with the exception of one in the college collection. Seeing that the musculature at the termination of the ileum is sphincteric in action, one may expect constrictions to occur at the ileo-caecal orifice similar to those which occur at the pylorus, but the only specimen I have seen which may represent such a lesion is No. $2522 \mathrm{~A}$ in the college museum. The preparation was obtained from a woman, aged 62 , who suffered from habitual constipation. The constriction at the ileo-caecal sphincter is supposed to result from syphilis, but there is no evidence that this is the case. In the specimen of congenital ileo-caecal occlusion the lumen of the ileum is closed $\frac{1}{2}$ in. above the ileo.caecal orifice.

\section{Congenital Occlusion of the Colon.}

This lesion is represented by only four preparations in the medical museums of London. In one the great intestine is absent beyond the hepatic flexure; in two the splenic flexure is represented merely by a thread which united the transverse and descending colons; in the fourth a septum occurs at the junction of the pelvic colon and rectum. Cougenital atresia of the colon is thus of uncommon occurrence; apparently the splenic flexure is the part most frequently affected. Atresia at the termination of the rectum is by far the most common point at which occlusion of the alimentary canal occurs. The specimens illustrating this lesion have been already described. ${ }^{19}$

REFERENCES.

1 Home, Sir Everard: Lectures on Comparative Anatomy, London, E 823 , vol, iii.

Lerche: Amer. Journ. Med. Sci., 1907, cxxxiv, p. 528.

Goldmann, E. E.: Lancet, 1906, vol. i, p. 21

Hertz, A. F.: BRITISH MEdical Jodrnal, 1908, vol. i, p. 130

5 Ehlers, H. W. E.: Virchow's Archiv fïr Path., Anat., und Physiol.,

ع907, Bd. 189, p. 512 .

Dhillips, J.: Archiv. of Pediatrics, 1908, xxv, p. 266

6 Ballantyne, J. W.: Manual of Antenatal Pathology, 1904, vol. ii.

Shattock, S. G.: Trans. Path. Soc., London, 1890, vol. xli, p. 87

Mackenzie, Morell: A Manual of Diseases of the Throat and Nose, London, 1884, vol. ii, p. 216

Griffith, J. P. C., and Lavenson, R. S.: Archiv, of Pediatrics, 1909, vol. xxvi, p. 161 .

Gray, H. M. : Lancet, 1908, vol. i, p. 549; vol. ii, p. 224.

Cunningham, D. J.: Trans..Roy. Soc. Edin., 1906, vol. xlv, part 1.

2 Robson, Mayo. Lancet. 1904, vol. i, p. 5 .

ISH Medical Jofrnal, 1904, vol. i, p. 413.

Forssn, Darm und Oesophagus Atvesien. Anatomische 15 , 1907, xxxiv, pp. 1-160.

Clogg: Lancet, 1904, vol. ii, 1770.

Bergallonne, Ch. J.: Rev. Mérd. lle la Suisse Rom, 1c07, t. xxvii, p. 960

17 Emmanuel, J. G.: Lancet, 1905, vol. ii. p. 440.

19 BRitish Medical Jotrnal, 1908, vol. ii, p. 1736.

AT its last meeting the Paris Académie des Sciences elected Sir Patrick Manson a corresponding member.

THE International American Congress of Medicine and Hygiene will be held on May 25th in Buenos Aires in commemoration of the first centenary of the May revolution of 1810. The President of the Congress will be Dr. Eliseo Canton, who, in conjunction with the Minister of the Argentine Republic at Washington, has appointed a Committee of Propaganda, of which Dr. Charles H. Frazier of Philadelphia is Chairman, and Dr. Alfred Reginald Allen of Philadelphia, Secretary. The work of the congress will be distributed among eight sections: Biology ; medicine; surgery; public hygiene; pharmacy and chemistry; sanitary technology; veterinary police; and dental pathology. There will also be an exhibition of nygiene. The official languages of the congress will be Spanish and English.

\section{A}

on

SOME ASPECTS OF POLIOMYELITIS.

Delivered at the National Hospital for the Paralysed and Epileptic; Drcember 14th, 1909.

$B Y$

SIR WILLIAM R. GOWERS, M.D., F.R.S.

Gentlenen,-If you were askeu the question, "What disease causes the most numerous mistakes in diagnosis?" your answer would probably depend on the character of your experience; but I think if you said "poliomyelitis" you would not be far from the truth. The errors to which it gives rise do not imply ignorance. They are due to the fact that the symptoms of the paralysis are so often preceded by others that resemble some general malady, and this is first supposed to exist, and to it the paralysis, when recognized, is often supposed to be secondary.

This danger does not always arise. In many of the cases, especially in those which arise in the early period of life, the paralysis comes on at the onset or at the second day of any general symptoms. There is then no room for error. But when the onset is after the infantile period, as the first three years of life may be termed, the generai initial symptoms are much more marked in character and more prolonged in duration. These misleading cases have seemed to be more freguent during recent years, and are certainly of sufficient frequency to justify a word of warn. ing. They occur at any period up to the completion of development, and sometimes even later. These patients are naturally able to describe their symptoms in greater detail, and so sometimes to add to the delusiveness which special symptoms confer upon them. I shall have some cases to show you which illustrate this fact.

I may mention another symptom which often causes error - the great pain in the limbs in the early stages, often accompanied by much tenderness. It may endure much longer, and is then attended with definite signs of inflam. mation of the nerves. In the early stage much fever accompanies the pain, and it is easy to think that the symptoms indicate rheumatic fever; to which it is easy to think that the spinal cord affection is secondary. This is probably always a mistake. I saw a case not long ago in whom the febrile disturbance of the disease lasted for a fortnight, and a diagnosis of typhoid fever was made to which the spinal affection was thought to be secondary. In such cases it is easier not only to say but to think that the original diagnosis was correct, and the spinal affection was really secondary to it. Many diagnostic errors are made in a kind of honesty over which the mind glides easily to a wrong conclusion.

Moreover, a mistake is often rendered easy by the severity of the initial symptoms; they naturally cause prostration. The area affected, by the paralysis is usually at first wide, sometimes almost universal, and only the return of power in some part shows that it cannot be ascribed to mere prostration. Those of you who have already had some experience of practice will realize how firmly rooted an idea may be about the nature of a child's illness in the maternal mind, especially if it was originally formed after a consultation with the mind of an older individual of the same sex. I remember once seeing a child with severe paralysis of this form whose mother had allowed it to go on for three months before she thought it worth while to see a doctor.

The disease was formerly known as infantile spinal paralysis because it chiefly occurred during the first three years of life, but cases later in life seem to have been more frequent in recent years, and during the last ten or fifteen years it has been observed to occur in apparent epidemics. In consequence, the pathology of the disease has attracted much attention, and our knowledge of it has been found to be most defective.

The epidemics of the disease have varied much in their extent, but all have occurred during or just after the hot season of the year. This is not a new feature; it has always been so with the sporadic form. As I expressed it many years ago, two thirds of the cases occur during the 